Full Paper

\title{
Second Law Analysis of a non-Newtonian Laminar Falling Liquid Film Along an Inclined Heated Plate
}

\author{
Rama Subba Reddy Gorla ${ }^{1, *}$ and David M. Pratt ${ }^{2}$ \\ 1 Cleveland State University, Cleveland, OH 44115 U.S.A.; E-Mail: r.gorla@ csuohio.edu \\ 2 Thermal Structures Branch, Air Vehicles Directorate, Air Force Research Laboratory, Wright \\ Patterson Air Force Base, Ohio 45433 U.S.A; E-Mail: David.Pratt@wpafb.af.mil \\ * Author to whom correspondence should be addressed.
}

Received: 11 January 2007 / Accepted: 20 February 2007 / Published: 30 March 2007

\begin{abstract}
The second law analysis of heat transfer of a non-Newtonian, laminar falling liquid film along an inclined heated plate is investigated. The upper surface of the liquid film is considered free and adiabatic. Velocity and temperature profiles are obtained analytically and used to compute the entropy generation number $\left(\mathrm{N}_{\mathrm{s}}\right)$, irreversibility ratio $(\Phi)$ and the Bejan number $(\mathrm{Be})$ for several values of the viscous dissipation parameter $\left(\mathrm{Br} \Omega^{-1}\right)$, viscosity index $(\mathrm{n})$ and the dimensionless axial distance $(\mathrm{X})$. The Bejan number increases in the transverse direction and decreases as the viscous dissipation parameter $\left(\mathrm{Br} \Omega^{-1}\right)$ increases. The numerical results show that the Bejan number decreases as the viscous dissipation parameter $\left(\mathrm{Br} \Omega^{-1}\right)$, Peclet number $(\mathrm{Pe})$ and the viscosity index (n) increase.
\end{abstract}

Keywords: Second law, Falling liquid film, heat transfer, Non-Newtonian fluids, Bejan number.

\section{Nomenclature}

$\begin{array}{ll}\mathbf{A} & \text { thermal diffusivity, } \mathrm{m}^{2} / \mathrm{s} \\ \mathbf{B r} & \text { Brinkman Number, } \mu^{2}{ }_{\mathrm{m}} / \lambda \Delta \mathrm{T} \\ \mathbf{B r} \mathbf{\Omega}^{-1} & \text { viscous dissipation parameter } \\ \mathbf{B e} & \text { Bejan Number } \\ \mathbf{C}_{\mathbf{p}} & \text { specific heat, } \mathrm{J} / \mathrm{kg} \mathrm{K}\end{array}$




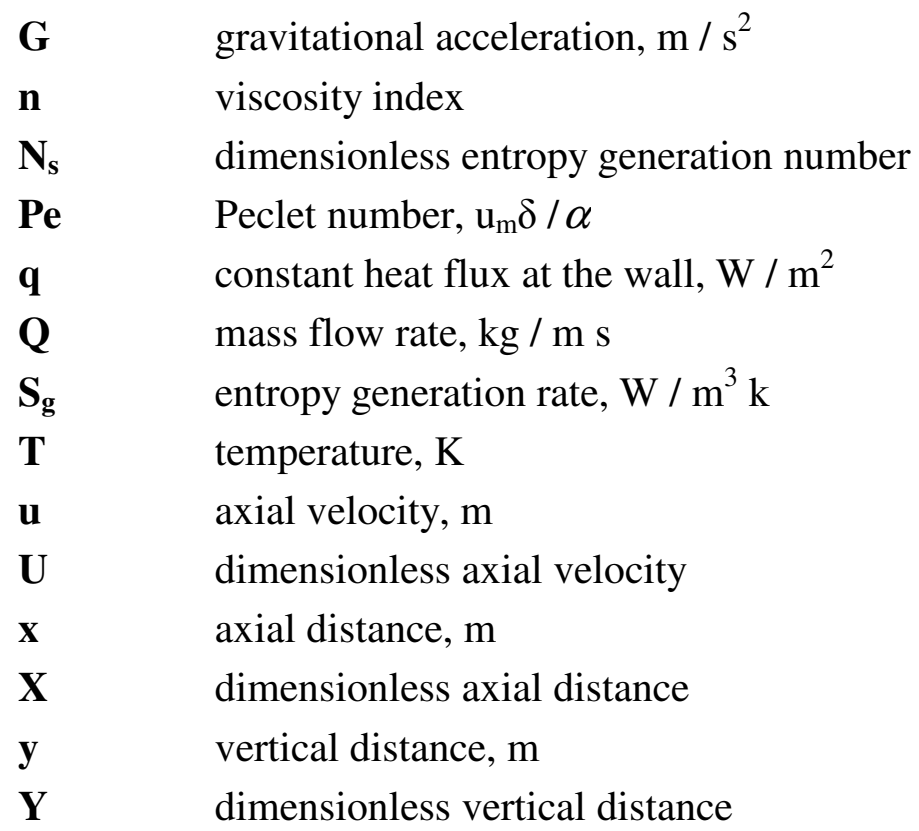

Greek Symbols

$\begin{array}{ll}\boldsymbol{\delta} & \text { liquid film thickness, } \mathrm{m} \\ \boldsymbol{\Delta} \mathbf{T} & \text { reference temperature difference, } \mathrm{K} \\ \boldsymbol{\theta} & \text { inclination angle, radian } \\ \boldsymbol{\Theta} & \text { dimensionless temperature } \\ \mathbf{k} & \text { thermal conductivity, } \mathrm{W} / \mathrm{m} \mathrm{K} \\ \boldsymbol{\mu} & \text { dynamic viscosity, Pa. s } \\ \boldsymbol{\Omega} & \text { dimensionless temperature difference, } \Delta \mathrm{T} / \mathrm{T}_{0} \\ \boldsymbol{\Phi} & \text { irreversibility ratio } \\ \boldsymbol{\rho} & \text { density of the fluid, } \mathrm{kg} / \mathrm{m}^{3}\end{array}$

Subscripts
m maximum value
0 reference value

\section{Introduction}

The study of second law analysis of a non-Newtonian, laminar falling liquid film along an inclined heated plate has many significant applications in thermal engineering and industries. Starting from petroleum drilling equipment to various industrial exchanger systems, this type of geometry can be observed. Meanwhile, the improvement in thermal systems as well as energy utilization during the convection in any fluid is one of the fundamental problems of the engineering processes, since improved thermal systems will provide better material processing, energy conservation and environmental effects [1]. One of the methods used for predicting the performance of the engineering processes is the second law analysis. The second law of thermodynamics is applied to investigate the irreversibility in terms of the entropy generation rate. Since the entropy generation is a measure of the 
destruction of the available work of the system, the determination of the active sites motivating the entropy generation is also important in upgrading the system performances. This method was introduced by Bejan [2, 3], Bejan and Tien [4] and Bejan [5]. The method was followed by many other investigators e.g. [6, 7].

Saouli and Aiboud-Saouli [7] applied the second law analysis for the Newtonian, laminar falling liquid film along an inclined heated plate. They considered the upper surface of the liquid film free and adiabatic and the lower wall fixed with constant heat flux. Their results show that the entropy generation number and the irreversibility ratio decrease in the transverse direction and increases as the viscous dissipation parameter $\left(\mathrm{Br} \Omega^{-1}\right)$ increases. Their results revealed the possibility of irreversibility ratio $\boldsymbol{\Phi} \geq 1$ i.e. the fluid friction irreversibility dominates over the heat transfer irreversibility. Recently, Saouli et. al. [8] investigated the entropy generation in a laminar, gravity-driven conducting liquid film along an inclined heated plate in the presence of a transverse magnetic field.

Entropy generation is closely associated with thermodynamic irreversibility, which is encountered in all the heat transfer processes. Different sources are responsible for entropy generation such as the heat transfer in the presence of temperature difference and the viscous dissipation $[2,3]$. The analysis of entropy generation rate in a circular duct with imposed heat flux at the wall and its extension to determine the optimum Reynolds number as a function of the Prandtl number and the duty parameter were presented by Bejan [3, 4]. Sahin [9] introduced the second law analysis to a viscous fluid in a circular duct with isothermal boundary conditions. Sahin [10] presented the effect of variable viscosity on the entropy generation rate for the heated circular duct. A comparative study of the entropy generation rate inside ducts of different shapes and the determination of the optimum duct shape subjected to the isothermal boundary condition was performed by Bejan [11]. Narusawa [12] gave an analytical and numerical analysis of the second law for the fluid flow and the heat transfer inside a rectangular duct. Mahmud and Fraser [13, 14] applied the second law analysis to fundamental convective heat transfer problems and to a non-Newtonian fluid flow through channel comprising two parallel plates.

The present investigation was undertaken in order to study the second law analysis of a nonNewtonian, laminar falling liquid film along an inclined heated plate. The velocity distribution was determined by solving the momentum equation subject to an appropriate set of boundary conditions and the initial conditions. The temperature distribution was determined by solving the energy equation. The entropy generation rate was evaluated and the entropy generation number, irreversibility ratio and the Bejan number were computed. The dimensionless parameters governing the problem are Brinkman number and Peclet number. Brinkman number represents the ratio of the work done against viscous shear stress to the heat transferred from the surface by fluid conduction. Peclet number is the ratio of inertial forces to thermal diffusivity.

\section{Mathematical Formulation and Analysis}

Consider an inclined heated plate placed in a parallel stream of a hydrodynamically fully developed non-Newtonian, laminar falling liquid film. Figure 1 shows the flow model and co-ordinate system. Neglecting the inertia terms in the momentum equation compared with the body force term, the momentum equation may be written as: 


$$
\mu \partial / \partial \mathrm{y}(\partial \mathrm{u}(\mathrm{y}) / \partial \mathrm{y})^{\mathrm{n}}+\rho g \sin \theta=0
$$

Using the boundary conditions of no slip at the wall and free upper surface, we may write:

$$
\text { No slip condition: } \mathrm{u}(0)=0
$$

$$
\text { Free surface condition: } \partial \mathrm{u}(\delta) / \partial \mathrm{y}=0
$$

Integrating the equation (1) with respect to y and using the boundary conditions (2a) and (2b), we have:

$$
\mathrm{u}(\mathrm{y})=\mathrm{u}_{\mathrm{m}}\left[1-(1-\mathrm{y} / \delta)^{(\mathrm{n}+1) /(\mathrm{n})}\right]
$$

where $u_{m}$ is defined as:

$$
\mathrm{u}_{\mathrm{m}}=[\rho \operatorname{gg} \sin \theta / \mu]^{1 / \mathrm{n}} \mathrm{n}(\delta)^{(\mathrm{n}+1) /(\mathrm{n})} /(\mathrm{n}+1)
$$

The liquid mass flow rate is:

$$
\mathrm{Q}={ }_{0} \int^{\delta} \rho \mathrm{u}(\mathrm{y}) \mathrm{dy}=\mathrm{u}_{\mathrm{m}} \rho \delta[(\mathrm{n}+1) /(2 \mathrm{n}+1)]
$$

Eliminating $\mathrm{u}_{\mathrm{m}}$ between equation (4) and (5) we obtain the liquid film thickness as function of the mass flow rate, dynamic viscosity, fluid density, gravitational acceleration and the angle of inclination of the plate:

$$
\begin{gathered}
\mathrm{u}_{\mathrm{m}}=\mathrm{Q}(2 \mathrm{n}+1) /(\mathrm{n}+1) \rho \delta=[\rho \operatorname{gsin} \theta / \mu]^{1 / \mathrm{n}} \mathrm{n}(\delta)^{(\mathrm{n}+1) /(\mathrm{n})} /(\mathrm{n}+1) \\
\delta=\left\{(2 \mathrm{n}+1) \mathrm{Q} \mu / \mathrm{n} \rho^{2} \mathrm{~g} \sin \theta\right\}^{(\mathrm{n}) /(2 \mathrm{n}+1)}
\end{gathered}
$$

The governing energy equation is given by:

$$
\mathrm{u}_{\mathrm{m}}\left[1-(1-\mathrm{y} / \delta)^{(\mathrm{n}+1) /(\mathrm{n})}\right] \partial \mathrm{T}(\mathrm{x}, \mathrm{y}) / \partial \mathrm{x}=\alpha \partial^{2} \mathrm{~T}(\mathrm{x}, \mathrm{y}) / \partial \mathrm{y}^{2}
$$

The inlet and boundary conditions given by:

$$
\text { Inlet condition: } \mathrm{T}(0, \mathrm{y})=\mathrm{T}_{0}
$$

Constant heat flux at the wall: $-\mathrm{k} \partial \mathrm{T}(\mathrm{x}, 0) / \partial \mathrm{y}=\mathrm{q}$

Adiabatic free surface: $\partial \mathrm{T}(\mathrm{x}, \delta) / \partial \mathrm{y}=0$

Proceeding with the analysis, we define the following dimensionless variables:

$$
\begin{gathered}
\mathrm{X}=\alpha \mathrm{x} / \mathrm{u}_{\mathrm{m}} \delta^{2} \\
\mathrm{Y}=\mathrm{y} / \delta \\
\mathrm{U}(\mathrm{Y})=\mathrm{u}(\mathrm{y}) / \mathrm{u}_{\mathrm{m}} \\
\Theta(\mathrm{X}, \mathrm{Y})=\left[\mathrm{T}(\mathrm{x}, \mathrm{y})-\mathrm{T}_{0}\right] / \Delta \mathrm{T}
\end{gathered}
$$

where

$\Delta \mathrm{T}=\mathrm{q} \delta / \mathrm{k}=$ reference temperature difference

$\mathrm{X}=$ dimensionless axial distance

$\mathrm{Y}=$ dimensionless vertical distance

$\mathrm{U}=$ dimensionless axial velocity

$\Theta=$ dimensionless temperature 
The energy equation may be written in a dimensionless form as:

$$
\left[1-(1-\mathrm{Y})^{(\mathrm{n}+1) / \mathrm{n}}\right]\{\partial \Theta(\mathrm{X}, \mathrm{Y}) / \partial \mathrm{X}\}=\partial^{2} \Theta(\mathrm{X}, \mathrm{Y}) / \partial \mathrm{Y}^{2}
$$

The transformed initial and boundary conditions may be written as:

$$
\begin{gathered}
\Theta(0,1)=0 \\
\partial \Theta(\mathrm{X}, 0) / \partial \mathrm{Y}=-1 \\
\partial \Theta(\mathrm{X}, 1) / \partial \mathrm{Y}=0 \\
\text { Now we assume } \Theta(\mathrm{X}, \mathrm{Y})=\Theta_{1}(\mathrm{X})+\Theta_{2}(\mathrm{Y})
\end{gathered}
$$

Using the separation of variables, we have:

$$
\begin{gathered}
\partial \Theta_{1} / \partial \mathrm{X}=\lambda \\
\left\{\partial^{2} \Theta_{2} / \partial \mathrm{Y}^{2}\right\} /\left[1-(1-\mathrm{Y})^{(\mathrm{n}+1) / \mathrm{n}}\right]=\lambda
\end{gathered}
$$

Integrating the equation (13) with respect to $X$ and using the boundary condition (11a), we have:

$$
\Theta_{1}=\lambda X
$$

From equation (24) we may write:

$$
\partial^{2} \Theta_{2} / \partial Y^{2}=\lambda\left[1-(1-Y)^{(\mathrm{n}+1) / \mathrm{n}}\right]
$$

Integrating equation (16) and using the boundary conditions given by equation (11) and using the entrance condition:

$$
{ }_{0} \int^{\delta} \Theta_{2} \partial \mathrm{Y}=0
$$

we have:

$$
\begin{array}{r}
\Theta_{2}=\left\{(2 n+1)\left[Z^{2} / 2-n^{2}(Z)^{(3 n+1) / n} /(2 n+1)(3 n+1)\right] /(n+1)-\right. \\
\left.(2 n+1)\left[1 / 6-n^{3} /(2 n+1)(3 n+1)(4 n+1)\right]\right\} /(n+1)(18)
\end{array}
$$

Substituting the value of $\lambda$ into equation (15), we get:

$$
\Theta_{1}=(2 n+1) X /(n+1)
$$

Using equation (12) we obtain:

$$
\begin{gathered}
\Theta(X, Y)=(2 n+1) X /(n+1)+(2 n+1)[Y(Y / 2-1)] /(n+1)-\left[n^{2}(1-Y)^{(3 n+1) / n}\right] / \\
(3 n+1)(n+1)-(2 n+1)\left[1 / 6-n^{3} /(2 n+1)(3 n+1)(4 n+1)-1 / 2\right] /(n+1)
\end{gathered}
$$

The entropy generation rate per unit volume $\mathrm{S}_{\mathrm{g}}$ “ $\left[\mathrm{W} / \mathrm{m}^{3} \mathrm{~K}\right]$ may be estimated by writing the second law of thermodynamic as:

$$
\begin{gathered}
\mathrm{S}_{\mathrm{g}}{ }^{\prime} \cdot \mathrm{c}=\mathrm{k}(\nabla \mathrm{T})^{2} / \mathrm{T}_{0}{ }^{2}+\mu[\partial \mathrm{u}(\mathrm{y}) / \partial \mathrm{y}]^{\mathrm{n}+1} / \mathrm{T}_{0} \\
=\mathrm{k}\left[(\partial \mathrm{T}(\mathrm{x}, \mathrm{y}) / \partial \mathrm{x})^{2}+(\partial \mathrm{T}(\mathrm{x}, \mathrm{y}) / \partial \mathrm{y})^{2}\right] / \mathrm{T}_{0}{ }^{2}+\mu[\partial \mathrm{u}(\mathrm{y}) / \partial \mathrm{y}]^{\mathrm{n}+1} / \mathrm{T}_{0}
\end{gathered}
$$




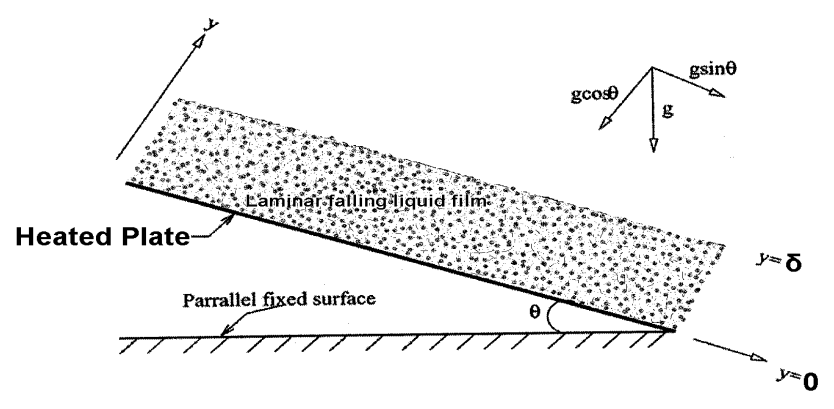

Figure 1. Flow Model and Co-ordinate system

\section{Results and Discussion}

The temperature distribution in the non-Newtonian, laminar falling liquid film is illustrated by Figure 2 for $n=0.5$. At a given transverse distance from the surface, fluid temperature increases in the longitudinal direction for a given value of the viscosity index (n).

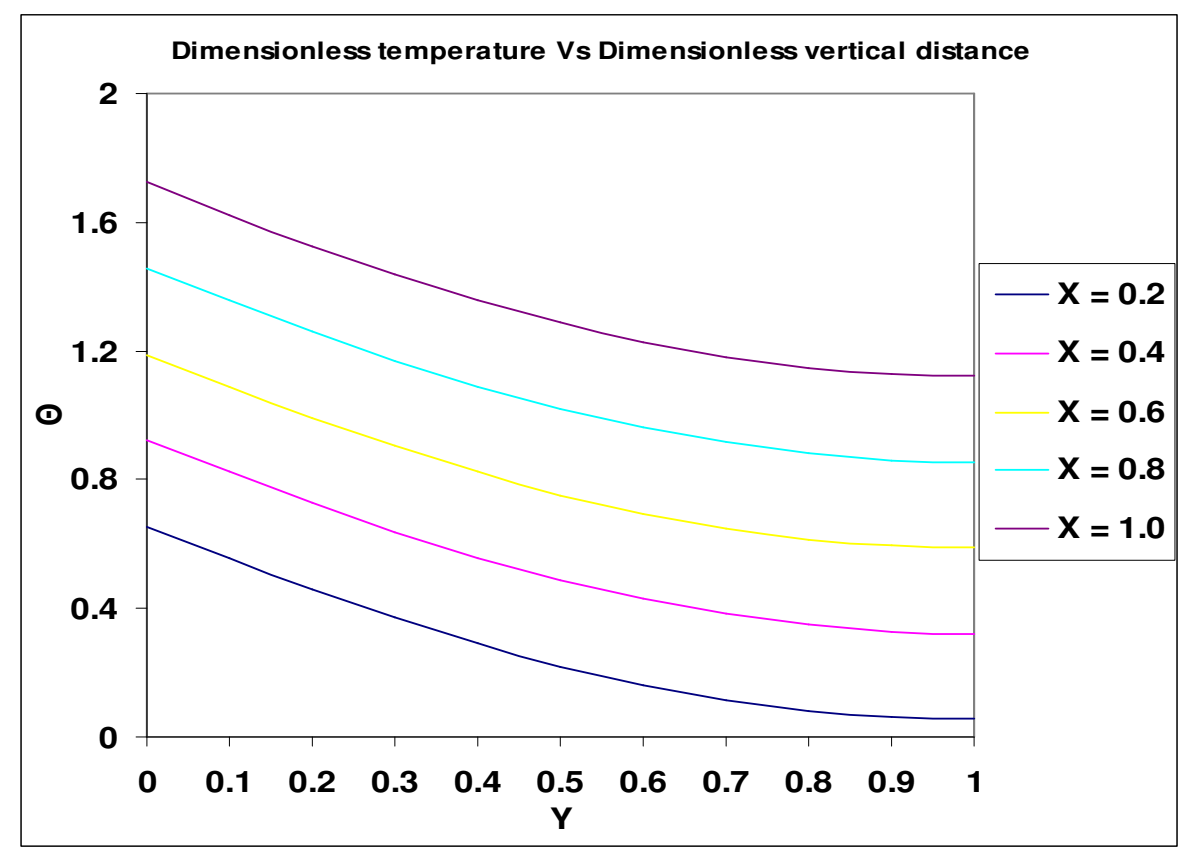

Figure 2. Temperature Profiles for $\mathrm{n}=0.5$

The viscous dissipation parameter $\left(\mathrm{Br} \Omega^{-1}\right)$ is defined as the product of the Brinkman number and the inverse of dimensionless temperature difference. We have,

Brinkman number $(\mathrm{Br})=\mu \mathrm{u}_{\mathrm{m}}^{2} / \mathrm{k} \Delta \mathrm{T}$ 
Dimensionless temperature difference $\Omega=\Delta \mathrm{T} / \mathrm{T}_{0}$

Viscous dissipation parameter $\left(\mathrm{Br} \Omega^{-1}\right)=\mu \mathrm{u}_{\mathrm{m}}^{2} \mathrm{~T}_{0} / \mathrm{k} \Delta \mathrm{T}^{2}$

The viscous dissipation parameter is an important dimensionless number for the irreversibility analysis. It determines the relative importance of the viscous effects for the entropy generation.

The entropy generation rate is given by:

$$
\mathrm{S}_{\mathrm{g}}{ }^{\prime}{ }^{\prime}=\mathrm{k}\left\{[\partial \mathrm{T}(\mathrm{x}, \mathrm{y}) / \partial \mathrm{x}]^{2}+[\partial \mathrm{T}(\mathrm{x}, \mathrm{y}) / \partial \mathrm{y}]^{2}\right\} / \mathrm{T}_{0}{ }^{2}+\mu[\partial \mathrm{u}(\mathrm{y}) / \partial \mathrm{y}]^{\mathrm{n}+1} / \mathrm{T}_{0}
$$

where $\mathrm{S}_{\mathrm{g}}{ }^{\prime}$ " = entropy generation rate per unit volume.

The dimensionless entropy generation number may be defined by the following relationship:

$\mathrm{N}_{\mathrm{S}}=\mathrm{kT}_{0}^{2} \mathrm{~S}_{\mathrm{g}} \cdot, \cdot / \mathrm{q}^{2}=\mathrm{N}_{\mathrm{C}}+\mathrm{N}_{\mathrm{Y}}+\mathrm{N}_{\mathrm{F}}$ where

$\mathrm{N}_{\mathrm{C}}=\{\partial \Theta(\mathrm{X}, \mathrm{Y}) / \partial \mathrm{X}\}^{2} / \mathrm{Pe}^{2}=$ entropy generated due to heat transfer in the axial direction $=\{(2 \mathrm{n}+1) \mathrm{X} /(\mathrm{n}+1)\}^{2} / \mathrm{Pe}^{2}$

$\mathrm{N}_{\mathrm{Y}}=\{\partial \Theta(\mathrm{X}, \mathrm{Y}) / \partial \mathrm{Y}\}^{2} / \mathrm{Pe}^{2}=$ entropy generated due to heat transfer in the transverse direction $=\left\{(2 n+1)[Y(Y / 2-1)] /(n+1)-\left[n^{2}(1-Y)^{(3 n+1) / n}\right] /(3 n+1)(n+1)-(2 n+1)\left[1 / 6-n^{3} /(2 n+1)(3 n\right.\right.$

$+1)(4 \mathrm{n}+1)-1 / 2] /(\mathrm{n}+1)\}^{2} / \mathrm{Pe}^{2}$

$\mathrm{N}_{\mathrm{F}}=\left(\mathrm{Br} \Omega^{-1}\right)(\partial \mathrm{U}(\mathrm{Y}) / \partial \mathrm{Y})^{\mathrm{n}+1}=$ entropy generation due to the fluid friction $=\left(\mathrm{Br} \Omega^{-1}\right)(\partial \mathrm{U}(\mathrm{Y}) / \partial \mathrm{Y})^{\mathrm{n}+1}=\left(\mathrm{Br} \Omega^{-1}\right)\left[(\mathrm{n}+1)(1-\mathrm{Y})^{1 /(\mathrm{n})} /(\mathrm{n})\right]^{\mathrm{n}+1}$

Here, the dimensionless parameters are:

$\mathrm{Pe}=\mathrm{u}_{\mathrm{m}} \delta / \alpha$

$\mathrm{Br}=\mu \mathrm{u}_{\mathrm{m}}^{2} / \mathrm{k} \Delta \mathrm{T}$ and

$\Omega=\Delta \mathrm{T} / \mathrm{T}_{0}=\left(\mathrm{T}_{\mathrm{W}}-\mathrm{T}_{0}\right) / \mathrm{T}_{0}$ are the Peclet number, Brinkman number and dimensionless temperature function, respectively.

The spatial distribution of the entropy generation number is plotted in Figures 3 and 4. We note that the entropy generation rate decreases in the transverse direction and approaches zero asymptotically because the upper surface of the liquid film is free and adiabatic. The entropy generation number increases as the viscous dissipation parameter $\left(\mathrm{Br}^{-1}\right)$ increases and decreases as Peclet number $(\mathrm{Pe})$ and the viscosity index (n) increases.

In convection problems, both the fluid friction and the heat transfer contribute to the rate of entropy generation. In order to assess whether the fluid friction or heat transfer dominates, a criterion known as the irreversibility ratio is defined by the following equation:

Irreversibility ratio $(\Phi)$ is the ratio of entropy generation due to the fluid friction to the total entropy generation due to heat transfer.

$$
\Phi=\mathrm{N}_{\mathrm{F}} /\left(\mathrm{N}_{\mathrm{C}}+\mathrm{N}_{\mathrm{Y}}\right)
$$

For $0 \leq \Phi<1$, the heat transfer dominates the irreversibility ratio and the fluid friction dominates when $\Phi>1$. The case where both the heat transfer and the fluid friction have the same contribution for the entropy generation is characterized by $\Phi=1$.

In Figures 5 and 6, irreversibility ratio is plotted as a function of the transverse distance for different values of the viscous dissipation parameter $\left(\mathrm{Br} \Omega^{-1}\right)$, viscosity index $(\mathrm{n})$ and the Peclet number 
(Pe). The irreversibility ratio decreases in the transverse direction and increases with viscous dissipation parameter $\left(\mathrm{Br}^{-1}\right)$.

Bejan number $(\mathrm{Be})$ is the ratio of heat transfer irreversibility to the total irreversibility due to heat transfer and fluid friction.

Bejan number $=\left(\mathrm{N}_{\mathrm{C}}+\mathrm{N}_{\mathrm{Y}}\right) /\left(\mathrm{N}_{\mathrm{C}}+\mathrm{N}_{\mathrm{Y}}+\mathrm{N}_{\mathrm{F}}\right)$

$$
=1 /(1+\Phi)
$$

In Figures 7 and 8, Bejan number profiles are shown as functions of the transverse distance for different values of the viscous dissipation parameter $\left(\mathrm{Br} \Omega^{-1}\right)$, viscosity index $(\mathrm{n})$ and the Peclet number (Pe). The Bejan number increases in the transverse direction and decreases as the viscous dissipation parameter $\left(\mathrm{Br} \Omega^{-1}\right)$ increases.

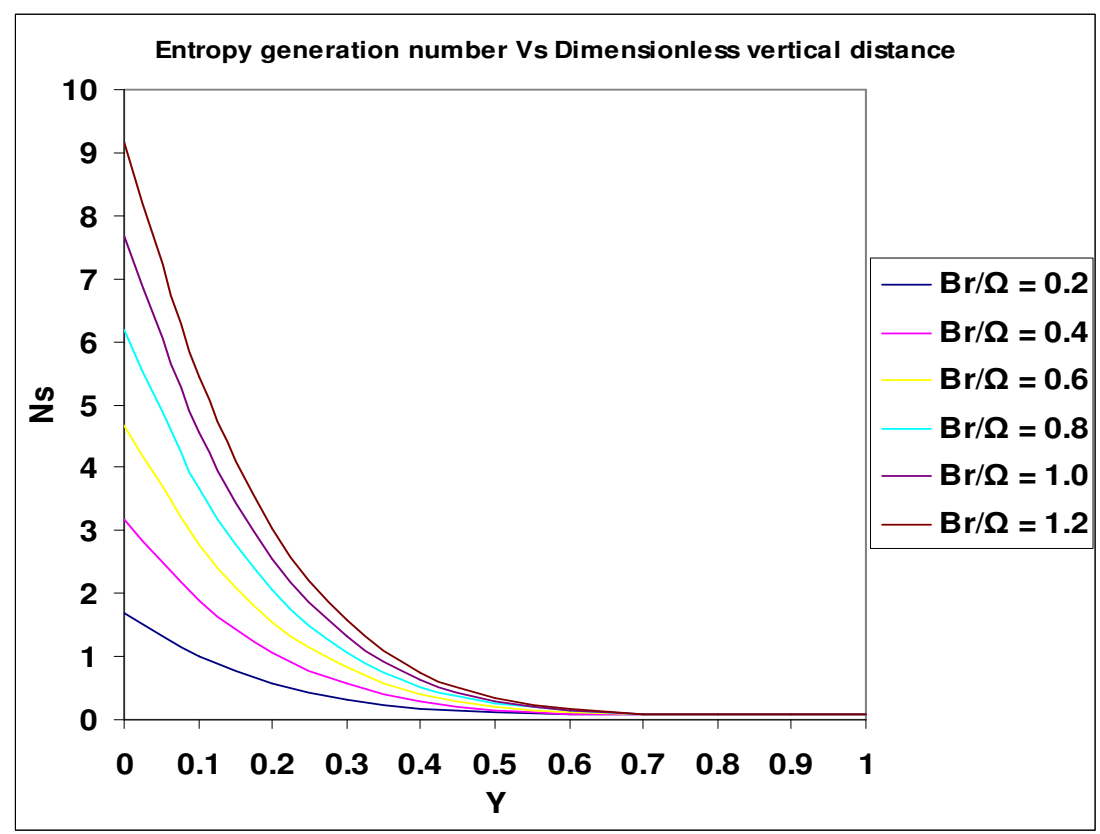

Figure 3. Entropy generation number (Ns) for $n=0 . .25$ and $\mathrm{Pe}=1.00$ 


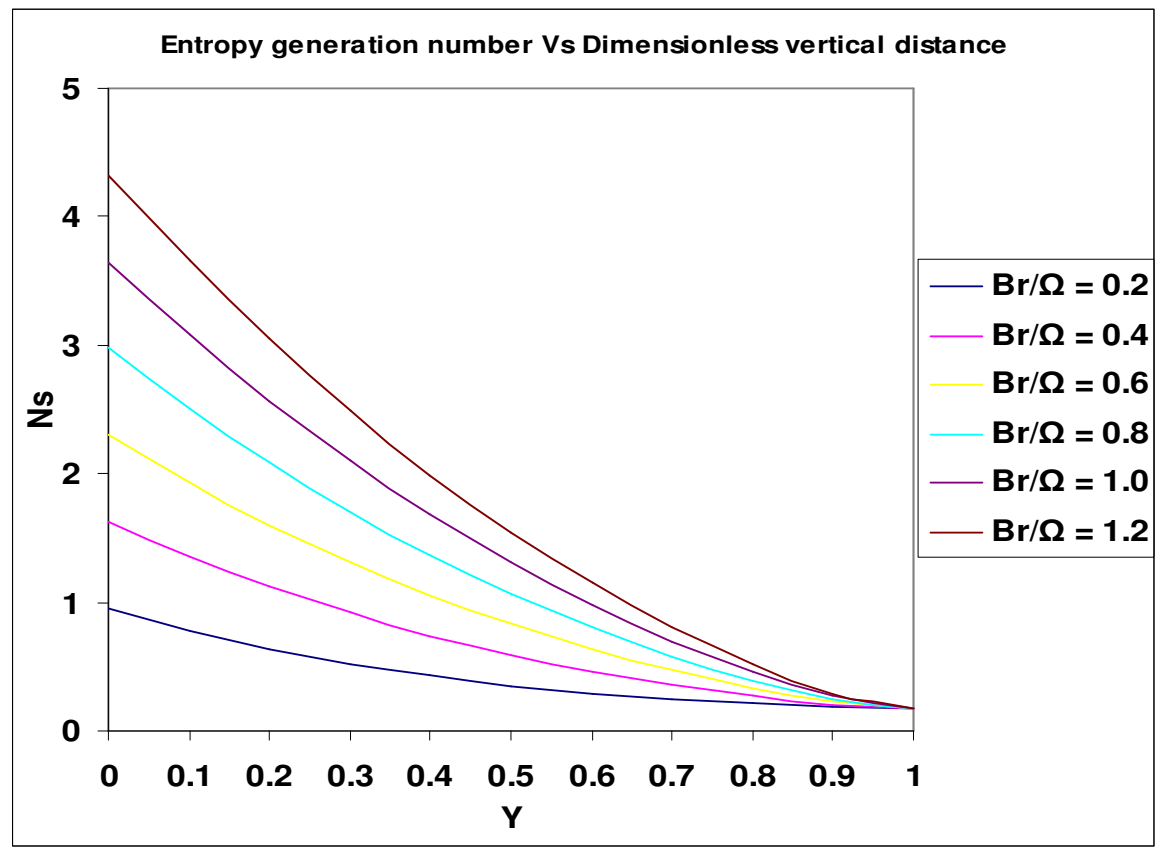

Figure 4. Entropy generation number (Ns) for $\mathrm{n}=2 . .00$ and $\mathrm{Pe}=1.00$

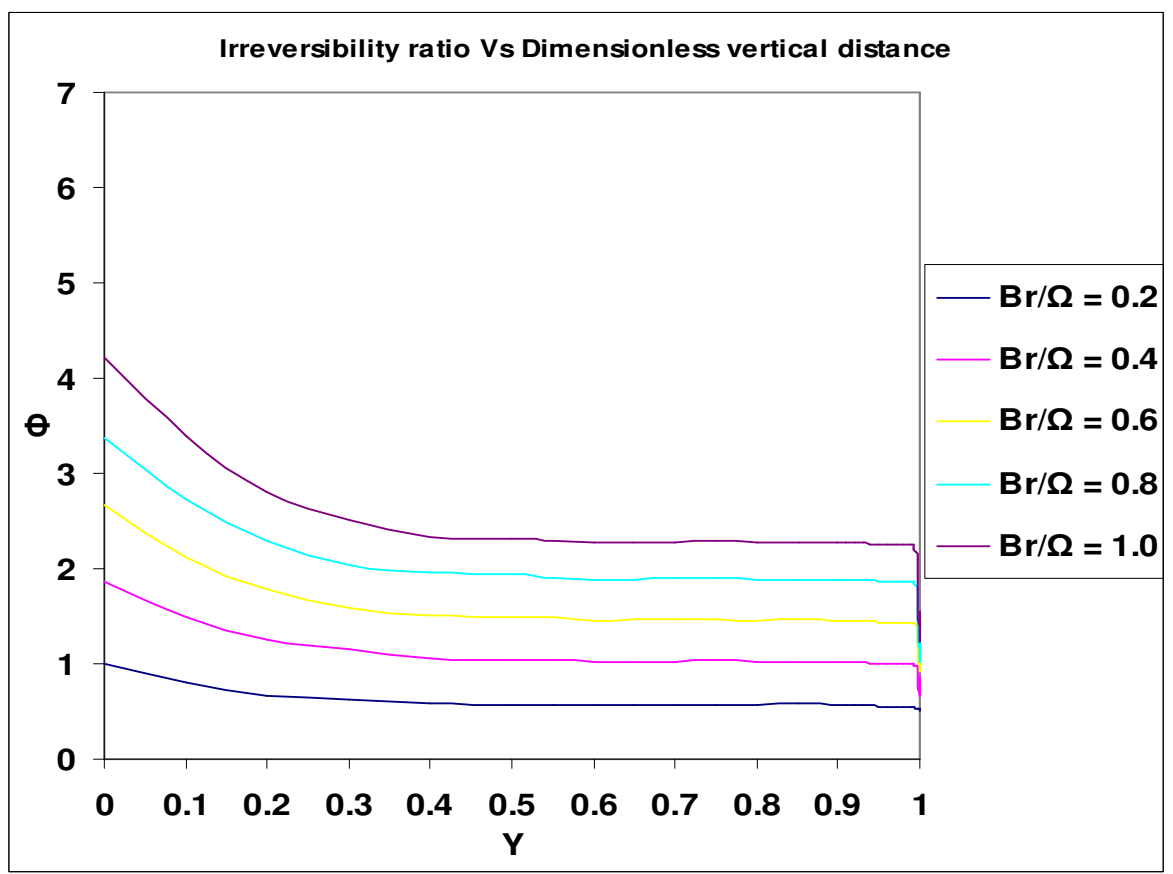

Figure 5. Irreversibility ratio $(\Phi)$ for $P e=0.50$ and $n=0.25$ 


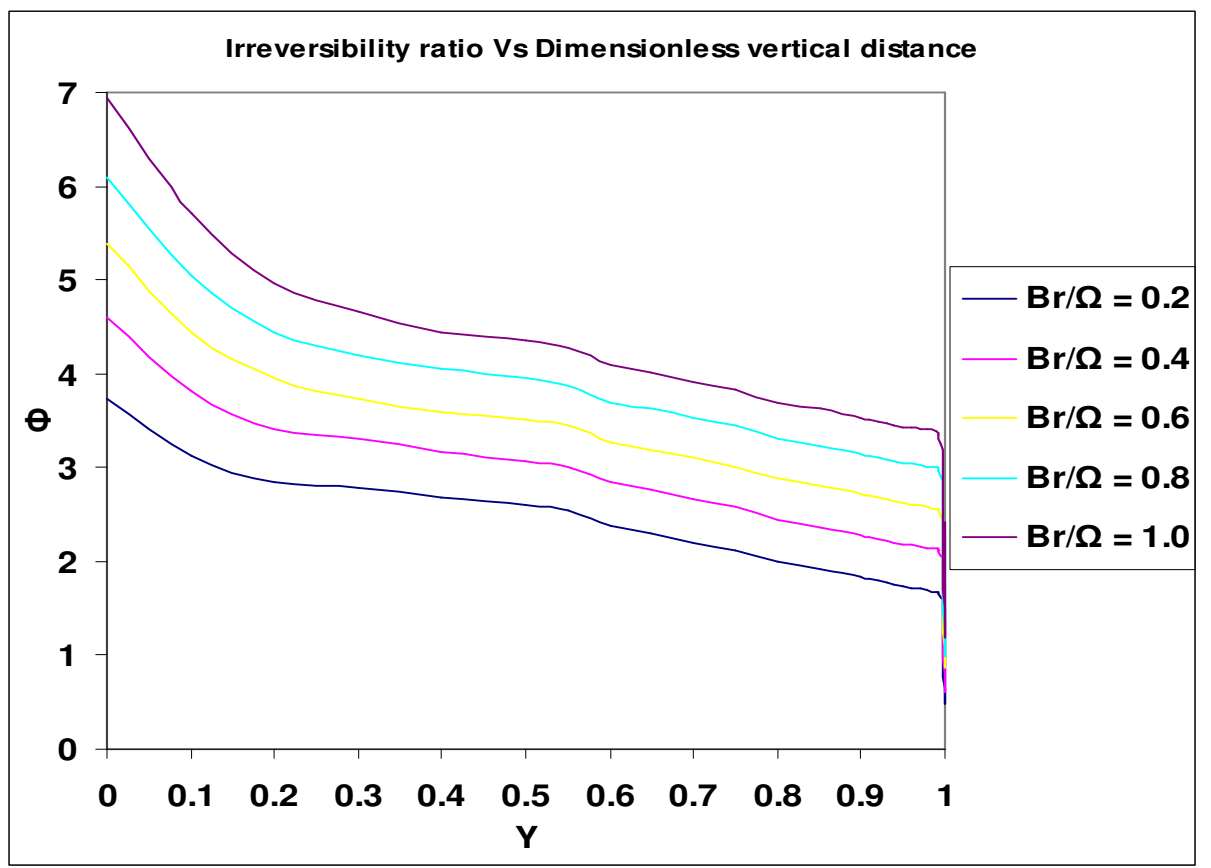

Figure 6. Irreversibility ratio $(\Phi)$ for $P e=0.50$ and $n=2.00$

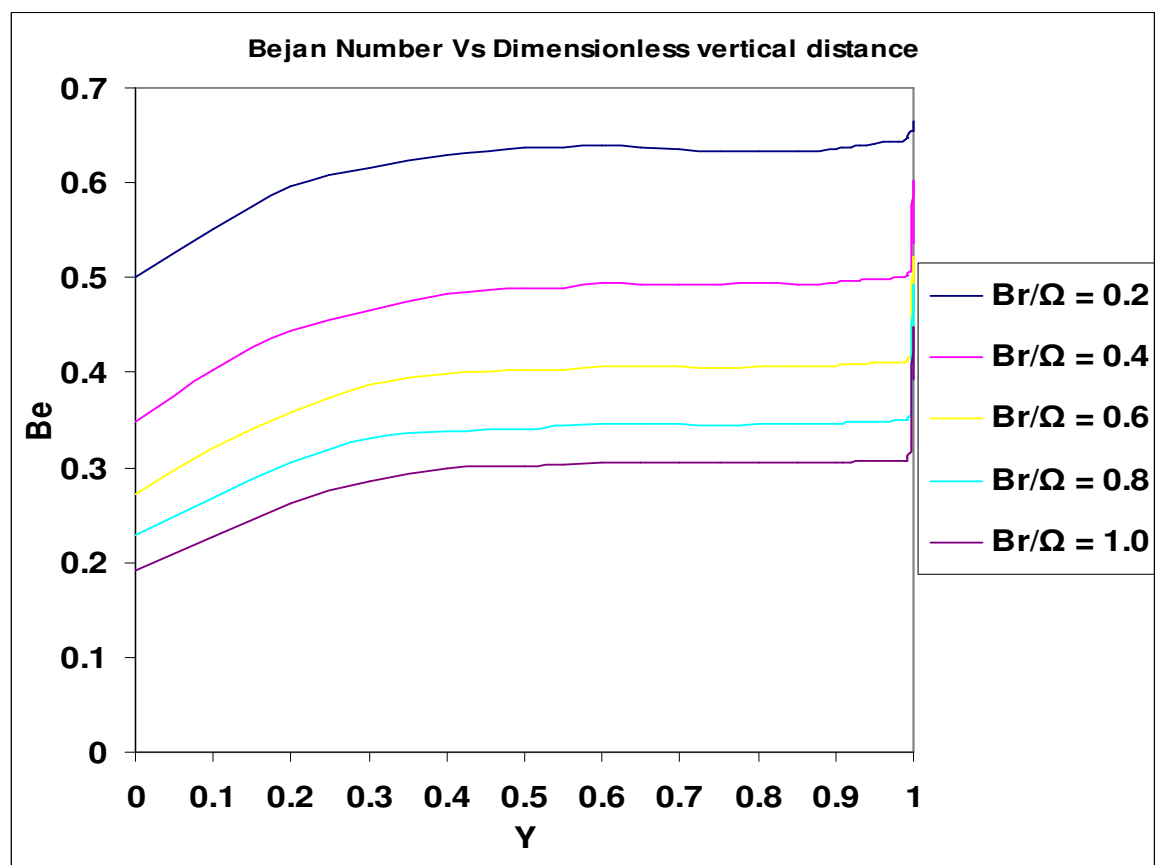

Figure 7. Bejan number $(\mathrm{Be})$ for $\mathrm{Pe}=0.50$ and $\mathrm{n}=0.25$ 


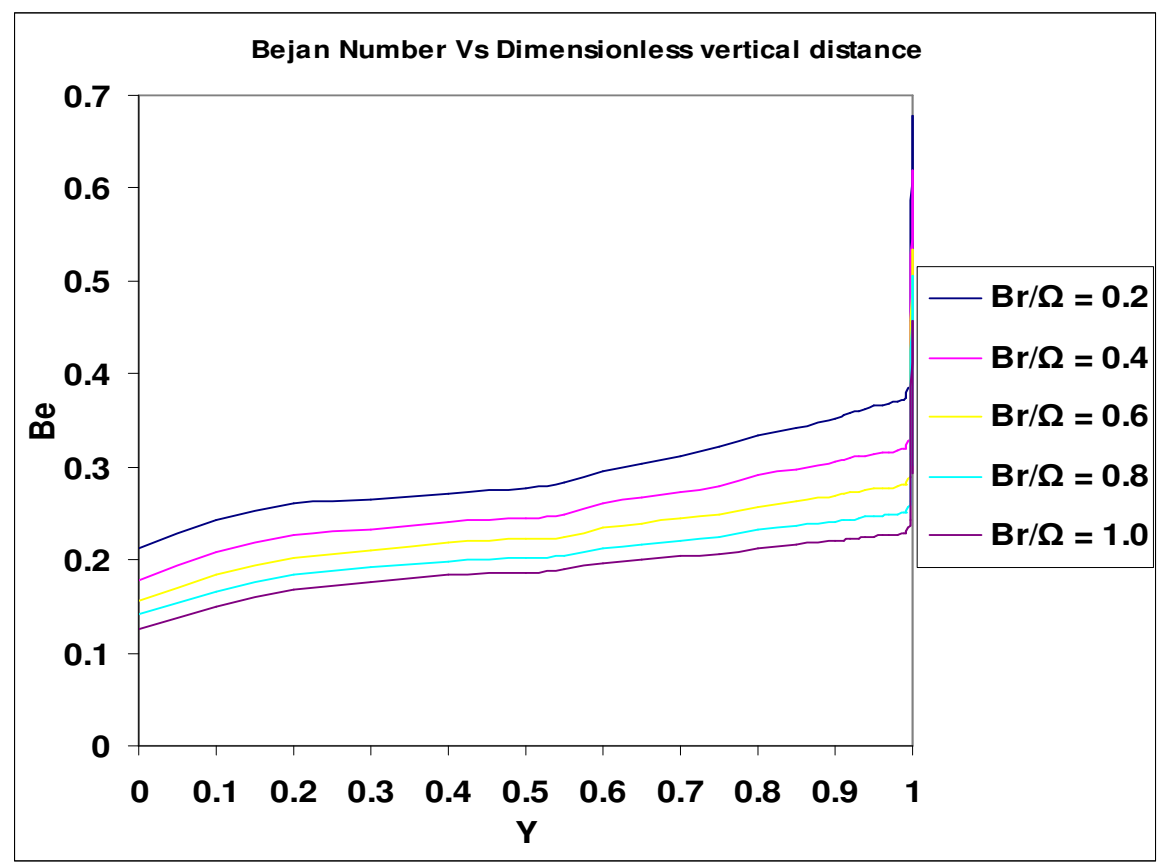

Figure 8. Bejan number $(\mathrm{Be})$ for $\mathrm{Pe}=0.50$ and $\mathrm{n}=2.00$

\section{Concluding Remarks}

This paper presents an application of the second law of thermodynamics to a non-Newtonian, laminar falling liquid film along an inclined heated plate. The velocity and the temperature profiles are obtained analytically and used to compute the entropy generation number, irreversibility ratio and the Bejan number for several values of the viscous dissipation parameter $\left(\mathrm{Br} \Omega^{-1}\right)$, viscosity index (n) and the dimensionless axial distance $(\mathrm{X})$. The numerical results show that the heat transfer dominates the irreversibility ratio when $(0 \leq \Phi<1)$ and the fluid friction dominates the heat transfer when $(\Phi>1)$. The case where both the heat transfer and the fluid friction have the equal contribution for the entropy generation is characterized by $(\Phi=1)$.

The Bejan number increases in the transverse direction and decreases as the viscous dissipation parameter $\left(\mathrm{Br} \Omega^{-1}\right)$ increases. The numerical results show that the Bejan number decreases as the viscous dissipation parameter $\left(\mathrm{Br} \Omega^{-1}\right)$, Peclet number $(\mathrm{Pe})$ and the viscosity index $(\mathrm{n})$ increases.

\section{References}

1. Makinde, O. D.; Osalusi, E. Second law analysis of laminar flow in a channel filled with saturated porous media. Entropy, 2005, 7, 148-160.

2. Bejan, A. Method of entropy generation minimization, or modeling and optimization based on combined heat transfer and thermodynamics. Revue Generale de Thermique, 1996, 35, 637-646.

3. Bejan, A. Entropy generation Minimization: The method of thermodynamic optimization of finitesize systems and finite-time processes. CRC Press, Boca Raton, New York (1996). 
4. Bejan, A.; Tien, C.-L. Natural convection in horizontal space bounded by two concentric cylinders with different end temperatures. International Journal of Heat and Mass Transfer 1979, 22, 919927.

5. Bejan, A. A Study of Entropy Generation in Fundamental Convective Heat Transfer. Journal of Heat Transfer, 1979, 101, 718-725.

6. Erbay, L.B.; Ercan, M. Ş.; Sülüş, B.; Yalçın, M. M. Entropy generation during fluid flow between two parallel plates with moving bottom plate. Entropy, 2003, 5, 506-518.

7. Saouli, S.; Saouli-Aïboud, S. Second law analysis of laminar falling liquid film along an inclined heated plate. International Communications in Heat and Mass Transfer, 2004, 31, 879-886.

8. Saouli-Aïboud, S.; Saouli, S.; Settou, N.; Meza, N. Thermodynamic Analysis of Gravity-driven Liquid Film along an inclined heated plate with Hydromagnetic and Viscous Dissipation Effects. Entropy, 2006, 8, 188-199.

9. Sahin, A. Z. Thermodynamics of laminar viscous flow through a duct subjected to constant heat flux. Energy, 1996, 21, 1179-1187.

10. Sahin, A. Z. Entropy generation in turbulent liquid flow through a smooth duct subjected to constant wall temperature. International Journal of Heat and Mass Transfer, 2000, 43, 1469-1478.

11. Bejan, A. Second law analysis in heat transfer. Energy, 1980, 5, 721-732.

12. Narusawa, U. The second law analysis of mixed convection in rectangular ducts. Heat and Mass Transfer 2001, 37, 197-203.

13. Mahmud, S.; Fraser, R. A. The second law analysis in fundamental convective heat transfer problems. International Journal of Thermal Sciences, 2003, 42, 177-186.

14. Mahmud, S.; Fraser, R. A. Thermodynamic analysis of flow and heat transfer inside channel with two parallel plates. Exergy, 2002, 2, 140-146.

(C) 2007 by MDPI (http://www.mdpi.org). Reproduction is permitted for noncommercial purposes. 